\title{
Uterine Reperfusion Ischemia and Use of Elastic Tourniquet
}

\author{
J. F. Nnang Essone ${ }^{1,2}$, F. Ovono Abessolo 3 , A. Tsagoulela3 ${ }^{3}$ G. Edjo Nkhilli4, P. Assoumou5, \\ J. A. Bang Ntamack5 ${ }^{5}$ E. Anyunzok ${ }^{6}$, U. Minkobames ${ }^{5}$, J. F. Meyes, E. Ngou Milama ${ }^{3}$ \\ ${ }^{1}$ Department of Physiology, Faculty of Medicine and Health Sciences, Libreville, Gabon \\ ${ }^{2}$ Department of Anesthesia Resuscitation Emergencies, University Hospital Center of Owendo, Owendo, Gabon \\ ${ }^{3}$ Department of Chemistry-Biochemistry, Faculty of Medicine and Health Sciences, Libreville, Gabon \\ ${ }^{4}$ Anesthesia Resuscitation Service Army Training Hospital, Libreville, Gabon \\ ${ }^{5}$ Department of Gynecology and Obstetrics, Faculty of Medicine and Health Sciences, Libreville, Gabon \\ ${ }^{6}$ Department of Mathematic and Biostatistic, Faculty of Medicine and Health Sciences, Libreville Gabon \\ Email: jfnnang@gmail.com
}

How to cite this paper: Nnang Essone, J.F., Ovono Abessolo, F., Tsagoulela, A., Edjo Nkhilli, G., Assoumou, P., Bang Ntamack, J.A., Anyunzok, E., Minkobame, U., Meye, J.F. and Ngou Milama, E. (2019) Uterine Reperfusion Ischemia and Use of Elastic Tourniquet. Journal of Biosciences and Medicines, 7, 98-119.

https://doi.org/10.4236/jbm.2019.72009

Received: January 3, 2019

Accepted: February 24, 2019

Published: February 27, 2019

Copyright (c) 2019 by author(s) and Scientific Research Publishing Inc. This work is licensed under the Creative Commons Attribution International License (CC BY 4.0).

http://creativecommons.org/licenses/by/4.0/

Open Access

\begin{abstract}
Introduction: In humans, it has not been established that the use of elastic tourniquet (ET) during myomectomies, whose delivery times do not exceed 90 minutes, which is responsible for ischemia reperfusion (I/R) systemic. Objectives: To study the plasma variations of markers of $I / R$ during myomectomies performed with ET, whose exposure time does not exceed 90 minutes. Population and methods: Plasma créatinin phosphokinase kinase (CPK) and gluthatione peroxydase (GPX) levels of patients with ET myoma $(M+G+, n=19)$, taken before, during and after exposure, were compared to those of women operated on myoma without tourniquet $(M+G-, n=15)$, carriers of unoperated myomas $(\mathrm{M}+\mathrm{G} 0, \mathrm{n}=20)$ and controls $(\mathrm{M} 0 \mathrm{G} 0, \mathrm{n}=$ 18). The duration of exposure of the ET was determined, and perioperative variations of GPX, $\mathrm{Ca}^{2+}, \mathrm{K}^{+}$and $\mathrm{CPK}$ between $\mathrm{M}+\mathrm{G}+$ and others groups were analyzed $(p<0.005)$. Results: The average duration of exposure of the ET was $51.56 \pm 14.12[30-88] \mathrm{min}$. In $\mathrm{M}+\mathrm{G}+$, prior to insertion, $\mathrm{CPK}$ was 71.64, GPX 3.537, $\mathrm{Ca}^{2+} 3.000, \mathrm{~K}^{+} 3.934$, and did not vary from those of $\mathrm{M}+\mathrm{G}$ $-\left(\mathrm{CPK}=59.354, \mathrm{GPX}=3.205, \mathrm{Ca}^{2+}=2.525, \mathrm{~K}^{+}=3.788\right), \mathrm{M}+\mathrm{G} 0(\mathrm{CPK}=$ 71.640, $\left.\mathrm{GPX}=2.759, \mathrm{Ca}^{2+}=3.004, \mathrm{~K}^{+}=3.934\right)$ and M0G0 (CPK $=57.2, \mathrm{GPX}$ $\left.=2.306, \mathrm{Ca}^{2+}=2.879, \mathrm{~K}^{+}=3.705\right)$. Conversely, during the posture $(\mathrm{CPK}=$ 95.665, GPX $\left.=3.645, \mathrm{Ca}^{2+}=3.642, \mathrm{~K}^{+}=4.757\right)$ and after the release of the ET $\left(\mathrm{CPK}=135.443, \mathrm{GPX}=3.694, \mathrm{Ca}^{2+}=3.892, \mathrm{~K}^{+}=5.322\right)$, these rates were higher among the $\mathrm{M}+\mathrm{G}+$ compared to the $\mathrm{M}+\mathrm{G} 0$ and M0G0, but did not differ from those of the $\mathrm{M}+\mathrm{G}-$ during $\left(\mathrm{CPK}=91.270, \mathrm{GPX}=3.413, \mathrm{Ca}^{2+}=\right.$ $\left.3.068, \mathrm{~K}^{+}=4.257\right)$ and after release $\left(\mathrm{CPK}=137.776, \mathrm{GPX}=3.632, \mathrm{Ca}^{2+}=\right.$
\end{abstract}


3.148, $\left.\mathrm{K}^{+}=5.075\right)$. Conclusion: The plasmatic concentration of ischemia $\left(\mathrm{CPK}, \mathrm{K}^{+}\right)$and reperfusion $\left(\mathrm{GPX}, \mathrm{Ca}^{2+}\right)$ biomarkers does not differ between $M+G+$ and $M+G-$, but is elevated relatively to controls (M0G0), but also to $\mathrm{M}+\mathrm{G} 0$ 's group. These results show that, for exposure times not exceeding 90 minutes, the elastic tourniquet is probably not the cause of the increase in plasma $I / R$ markers observed in $M+G+$ women. Moreover, these data suggest that the variations of the markers observed during the different surgical stages within each of the two groups of women $M+G+$ and $M+G$ - compared to those of the controls (M0G0) and unoperated myomas $(\mathrm{M}+$ G0) are due essentially to the surgical act.

\section{Keywords}

Ischemia, Reperfusion, Uterus, Elastic, Tourniquet

\section{Introduction}

Ischemia is the consequence of a decrease in blood flow in a given vascular territory [1] [2] [3] [4]. Reperfusion is the restoration of blood circulation in a tissue that has been previously subjected to ischemia [1]-[6]. In the post-ischemic period, the restoration of blood flow is essential to avoid irreversible damage. However, the latter can transform viable ischemic lesions into non-viable ones. The name ischemia-reperfusion (I/R or IR) recalls that tissue damage is a direct result of hypoxia-ischemia and indirectly reperfusion-reoxygenation [6] [7] [8] [9]. Outside medical situations [1] [2] [9] [10] [11], certain types of surgeries are providers of I/R phenomena [1] [12]-[17], this is the case of the use of the tourniquet during myomectomy [17] [18] [19] [20].

Myomectomy is a surgical procedure that allows patients to retain their uterus in the context of myomatous diseases [17]-[25]. Although common [17]-[22], the removal of myomas can be complicated by severe bleeding [18]-[25]. Despite controversies over the use of the tourniquet (ET) during this surgery, it remains an indispensable tool for many practitioners [17]-[23] [25]. Indeed, its use causes a temporary stop of the blood circulation, generating a bloodless operative field and allowing a surgical comfort [18]-[26]. This technique is thus commonly used for many young women of sub-Saharan Africa because of the sometimes voluminous and multiple leiomyomas [22] [24]. However, for some authors, the arterial ligation generated by the tourniquet is responsible for a temporary stop of the blood flow downstream, but also for tissue compression at its various points of passage. Ultimately, this circulatory interruption would lead downstream complications of $\mathrm{I} / \mathrm{R}$ causing tissue damage and cell necrosis may cause physiological dysfunction [1] [2] [3] [4] [6] [7] [8] [9] [17] [26]-[31]. During some non gynecological surgeries involving tourniquet, systemic complications have been described, most of which are attributed to the duration of the application and its relaxation [1] [12] [13] [14] [15]. For uterine surgery, 
the average time to apply tourniquet is 60 minutes, excluding periods of relaxation [18] [19] [20] [21] [23]. Or, at present, when using the ET, the time to onset of I/R at the uterine and systemic level is not completely known [18]-[26]. Indeed, animal model studies have found uterine I/R lesions appearing beyond the $2^{\text {nd }}$ hour in rats and at the 4 th hour in cynomolgus monkeys [32] [33]. On the human scale, several authors have described the phenomena of ischemia and reperfusion during myomectomy by ligation of the uterine arteries, but without being precise about the time of onset or their systemic expression [33]-[40]. We have initiated this work, because in humans, it is not clear that the elastic tourniquet times of less than 90 minutes are responsible for systemic I/R phenomena.

\section{Population and Methods}

\subsection{Population}

This was an observational, prospective, case-control study conducted in Libreville from January 2016 to January 2018 inclusive. It involved 72 people divided into four groups. The first group consisted of 19 women who had to undergo myoma surgery using the elastic tourniquet $(M+G+)$, while the second consisted of those who would benefit from a myomectomy without using the elastic tourniquet $(M+G-)$. The third group included women with unoperated myoma $(M+G 0)$, while healthy women formed the fourth group (control, MOG0).

This work has been done according to Helsinki's ethical recommendations on the use of living things [41]. Informed consent was obtained from women. In addition, they have been assured of the confidentiality of the data collected. In addition, we obtained prior authorizations from those responsible for the structures in which we conducted this study.

\subsubsection{Inclusion Criteria}

All women, regardless of age, with an indication of myomectomy (gynechological examination, pelvic echography) with or without tourniquet, as well as those with unoperated myomas (gynechological examination, pelvic echography), were included in this work after obtaining informed consent. Similarly, women in good health, with socio-demographic criteria superimposed on those of the patients and free from any medico-surgical condition were recruited (normal gynecological examination and pelvic echography).

\subsubsection{Non Inclusion Criteria}

All patient who refused to participate in the study and those who had at least one factor that could alter the plasma concentrations of the I/R markers were not included [1] [3] [5]. Moreover, myoma states with pregnancy, myomectomies performed in emergencies or complicating during the perioperative period, as well as all women who had presented a non-myomatous gynecological condition discovered on ultrasound had not been selected. Patients having deprogrammed 
their intervention on the day of the operation, as well as those who presented a modification of the anesthetic protocol (spinal or epidural anesthesia instead of general anesthesia) or surgical (laparoscopy, non-programmed elastic tourniquet) were excluded.

\subsection{Methods}

\subsubsection{Recruitment Method}

Patient recruitment was carried out in the anesthesia-resuscitation and obstetrics and gynecology departments of the main university hospitals in Libreville. The biological assays were carried out in the laboratory of the Angondjé University Hospital Center.

\subsubsection{Patients with Indication of Myomectomy ( $M+G+$ and $M+G-)$}

Patients scheduled for myomectomy (Gynecological examination, pelvic ultrasound by Mindray ${ }^{\mathrm{TM}}$, Bio-medical Electronics ${ }^{\circ}$ Co. Ltd.) were recruited for pre-anesthetic consultation. During this medical consultation they benefited from a clinical examination performed by an anesthesiologist. Patients who met the inclusion criteria were informed of the survey and its progress. They received a detailed study card and an informed consent form.

After the clinical evaluation of the consenting patients, the data collected was recorded in a medical file.

\subsubsection{Patients with Unoperated Myomas ( $M+$ G0)}

They were recruited during gynecological consultations. Consenting women received a general clinical examination (performed by an anesthesiologist), a gynecological examination with a pelvic ultrasound (Mindray ${ }^{\mathrm{TM}}$, Biomedical Electronics ${ }^{\circ}$ Co. Ltd.) made by a gynecologist, and then a blood test.

\subsubsection{Healthy Women (Controls, M0G0)}

They were recruited voluntarily, within the general population. Consenting women received a complete examination (gynecology and general) with a pelvic ultrasound (Mindray ${ }^{\mathrm{TM}}$, Bio-medical Electronics ${ }^{\circ}$ Co. Ltd.) and a blood test.

In total, during the study period, 120 women with eligibility criteria were collected, of whom 40 were operated on myoma with tourniquet $(M+G+)$, 35 operated on myoma without tourniquet $(M+G-), 25$ non-operated myoma carriers $(M+G 0)$ and 20 controls (M0G0). Of the 40 patients designated $M+G$ + selected, 21 were excluded for refusal of participation. The population of women $\mathrm{M}+\mathrm{G}+$ definitively retained was 19 people. On the other hand, among the 80 selected women who made up the other three groups, $15 \mathrm{M}+\mathrm{G}-, 20 \mathrm{M}+$ G0 and 18 M0G0 were included, while 27 women were not selected for refusal of participation and unavailability (Figure 1).

The data collected at the end of the clinical and ultrasound evaluation were recorded in a medical file. It was clinically relevant, from age (years), the morphological characteristics of the myoma (number, size in $\mathrm{mm}$ ), the duration of surgery and tourniquet (in minutes). At the biological level, they concerned 


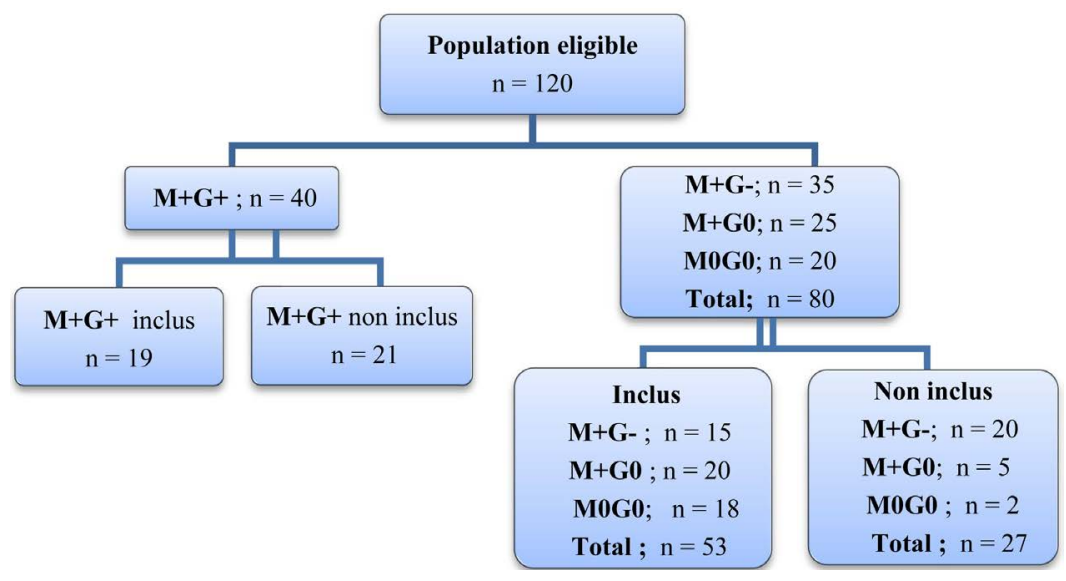

Figure 1. Diagram describing the selection of the working population.

the plasma concentrations of glutathione peroxidase (GPX, in $\mathrm{pg} / \mathrm{ml})$, creatine phosphokinase (CPK, in U/l, normal $95-105 \mathrm{U} / \mathrm{l})$, calcium $\left(\mathrm{Ca}^{2+}\right.$, in $\mathrm{mmol} / \mathrm{l}$, normal 2.2 at $2.6 \mathrm{mmol} / \mathrm{l})$ and potassium $\left(\mathrm{K}^{+}\right.$, in $\mathrm{mmol} / \mathrm{l}$, normal 3.5 to 4.5 $\mathrm{mmol} / \mathrm{l}$ ) [42]. The average plasma concentration of GPX obtained in controls (M0G0) was considered as a reference value [42] [43].

\subsubsection{Technique of the Installation of the Elastic Tourniquet}

The material used was a 16-gauge Foley ${ }^{\mathrm{TM}}$ brand elastic tourniquet set according to the method described by Rubin [17] [18] [19] [20] [21] [23]. According to this technique, the tourniquet passes through the broad ligament, near its base and outside the uterine vessels. Subsequently, it is tightened enough to obtain temporary haemostasis. The duration of exposure, according to the protocol used during the present investigation did not exceed 90 minutes (Photo 1). The tourniquet release was done after removal of all the myomas and once the uterine suture ended.

\subsubsection{Anesthetic Protocol}

It followed the recommendations of the American Society of Anesthesiology (ASA) [44]. It included pre-operative evaluation and intervention preparation without prior pharmacological premedication. All patients in our survey were classified ASA I [44]. The induction started after a pre-oxygenation of three minutes, by the injection of 3 micrograms per kilogram of weight of fentanyl, followed by 2 milligrams per kilogram of weight of propofol, then of 0.6 milligrams per kilogram of bromide weight. of rocuronium. After orotracheal intubation, maintenance was $0.6 \%$ to $1.5 \%$ isoflurane with mechanical ventilation, with reinfusion of fentanyl if necessary. The measurement of hemodynamic parameters was done during the pre-anesthetic consultation and during the per and postoperative period (Philipps IntelliVue MP $40^{\mathrm{TM}}$-Ireland). Waking up and postoperative management was traditional [44].

\subsubsection{Blood Collection and Conditioning Methods}

Three (3) types of tubes were used during this investigation (Dry, heparin, 




Photo 1. Elastic tourniquet technique according to Rubin [17] [18] [19] [20] [21] [23].

EDTA). Thus, a 22-gauge catheter (Jelco ${ }^{\circ}$ Smith's Medical ${ }^{\mathrm{TM})}$ was taken from each participant to collect $3 \mathrm{ml}$ of peripheral venous blood per tube. For the $\mathrm{M}+$ $\mathrm{G}+$ patients, the sampling rate was five minutes after removal of all the myomas, and 15 minutes after the release of the withers. That of women $M+G-$ was five minutes after removal of all myomas and 15 minutes after suture of the uterus. In the women M0G0 and M + G0, a one-off sampling was performed. The collected blood was sent to the laboratory, where it was immediately centrifuged at $4000 \mathrm{rpm}$ (Universal $320^{\mathrm{TM}}$, Hettich Zentrifugen ${ }^{\circ}$, Germany). Plasma collected was placed in cryovials (Biologix ${ }^{\mathrm{TM}}$, Biologix Inc. USA) and stored in a freezer (Thermo Scientific Forma $900^{\mathrm{TM}}$ Series, Thermo Fisher Scientific Inc.) at $-86^{\circ} \mathrm{C}$.

\subsubsection{Dosage of the GPX}

It was dosed manually by ELISA (Enzyme linked immunosorbent assay) technique. To do this, we used a kit from the Elabscience ${ }^{\oplus}$ laboratory. This assay was performed according to a procedure previously described [43]. One hundred $(100 \mu \mathrm{l})$ serum was placed in the wells containing GPX monoclonal antibody. Subsequently, the plate was covered with an adhesive film of cellophane and incubated for 90 minutes at $37^{\circ} \mathrm{C}$. After this incubation and removal of the liquid, $100 \mu \mathrm{l}$ of biotinylated $\mathrm{AB}$ working solution was added. The wells were again covered and reincubated for 1 hour at $37^{\circ} \mathrm{C}$. After this incubation, the wells were washed 3 times with $350 \mu$ of washing buffer. At the end of this treatment, $100 \mu \mathrm{l}$ of peroxidase (HRP) were placed in each well, followed by another incubation at $37^{\circ} \mathrm{C}$. for 30 minutes. Following this step, we performed 5 washing operations as previously described, then $90 \mu \mathrm{l}$ of substrate were added to each well. Thirty minutes later, the solution turned blue, then $50 \mu$ of the stop solution was added to each well. The last step was to read the optical density at 450 nanometers (PR $3100^{\mathrm{TM}}$ reader, BIORAD ${ }^{\circ}$ ). The plasma concentrations of GPX were obtained by comparison with a standard range that had been treated at the same time as the samples.

\subsubsection{Determination of CPK, Calcemia and Serum Potassium}

For the determination of the total serum concentration of $\mathrm{CPK}$, ready-to-use 
reagents were used (COBAS C $311^{\mathrm{TM}}$ Automaton, Roche Hitachi, Germany). Reflection densities were monitored during incubation. The rate of change of the reflection density was then converted to enzymatic activity. The reaction was read spectrophotometrically. The determination of serum potassium and potassium was performed on a controller (Audicom ${ }^{\circ}$ AC $9900^{\mathrm{TM}}$, USA) by colorimetry [42].

\subsubsection{Statistical Methods}

The data, once collected on a survey sheet, was entered on a Microsoft Excel $2010^{\circ}$ file and analyzed using the Center for Deseases Control (CDC) EPI INFO $7^{\circ}$ software. The descriptive study was made using averages, proportions and standard deviations calculations. To compare the proportions between them, we used the chi-2 and Anova test. The threshold of statistical significance was 5\% (p $<0.05)$.

\section{Results}

\subsection{Sociodemographic and Clinical Parameters of the Working Population}

The socio-demographic and clinical parameters of the study population are summarized in Table 1 . The mean age of the $M+G+$ patients was $34.78 \pm 5.28$ years old. Taking into account other groups of women, it was $37.78 \pm 6.04$ years for $M+G-, 37.25 \pm 7.54$ years and $35.83 \pm 6.15$ years for M + G0's and M0G0 respectively. The mean duration of myomectomy without tourniquet was 108.93 $\pm 85.795 \mathrm{~min}$, compared to $105.72 \pm 34.55$ with tourniquet $(\mathrm{p}=0.060)$. That of the tourniquet was $51.56 \pm 14.12$ [20 - $82 \mathrm{~min}$ ]. Six women had more than 10 myomas in the $\mathrm{M}+\mathrm{G}+$ group, compared to one in the $\mathrm{M}+\mathrm{G}$ - group. Mean myoma size was $23 \mathrm{~mm}$ in $\mathrm{M}+\mathrm{G}+$ patients compared to $18.26 \mathrm{~mm}$ in $\mathrm{M}+\mathrm{G}-$ patients.

Table 1. Intraoperative sociodemographic and clinical parameters of the study population.

\begin{tabular}{|c|c|c|c|c|}
\hline \multirow{2}{*}{ Variables } & \multicolumn{4}{|c|}{ Study population } \\
\hline & $M+G+$ & $M+G$ & $\mathrm{M}+\mathrm{G} 0$ & M0G0 \\
\hline Numbers & 19 & 15 & 20 & 18 \\
\hline Age $($ Mean $\pm S D)$ & $34.78 \pm 5.28$ & $37.78 \pm 6.04$ & $37.25 \pm 7.54$ & $35.83 \pm 6.15$ \\
\hline Length of tourniquet (Mean $\pm S D$ ) & $51.56 \pm 14.12$ & & - & - \\
\hline Duration of Surgery (Mean \pm SD) & $105.72 \pm 34.55$ & $108.93 \pm 85.8$ & - & - \\
\hline Number of myoma & & & - & - \\
\hline$<10$ & 13 & 14 & 20 & - \\
\hline$>10$ & 6 & 1 & - & \\
\hline Myoma size (Average, mm) & 23.11 & 18.26 & 9.7 & - \\
\hline
\end{tabular}




\subsection{Comparison of Plasma Concentrations of GPX, CPK, $\mathrm{Ca}^{2+}, \mathrm{K}^{+}$ of Control Women (MOG0) to Women with Unoperated Myoma (M + G0)}

The average plasma concentration of CPK was $57.208 \mathrm{U} / \mathrm{l}$ in M0G0, compared to $71.64 \mathrm{U} / \mathrm{l}$ in $\mathrm{M}+\mathrm{G} 0(\mathrm{p}=0.118)$. GPX was $2.306 \mathrm{pg} / \mathrm{ml}$ in M0G0, compared with $3.567 \mathrm{pg} / \mathrm{ml}$ in $\mathrm{M}+\mathrm{G} 0(\mathrm{p}=0.0001)$. Mean plasma concentration of $\mathrm{Ca}^{2+}$ was $2.879 \mathrm{mmol} / \mathrm{l}$ in M0G0 against $3.00 \mathrm{mmol} / \mathrm{l}$ in $\mathrm{M}+\mathrm{G} 0(\mathrm{p}=0.683)$. That of $\mathrm{K}^{+}$ was $3.705 \mathrm{mmol} / \mathrm{l}$ in M0G0's, compared with $3.934 \mathrm{mmol} / \mathrm{l}$ in $\mathrm{M}+\mathrm{G} 0$ 's ( $\mathrm{p}=$ 0.219) (Table 2).

\subsection{Comparison of Plasma Concentrations of GPX, CPK, $\mathrm{Ca}^{2+}, \mathrm{K}^{+}$ Obtained in Patients with Myomectomy Using Elastic Tourniquet $(\mathrm{M}+\mathrm{G}+$ ) Compared to Control Women (M0G0)}

The average plasma concentration of CPK was $57.21 \mathrm{U} / \mathrm{l}$ in M0G0, whereas it was $71.64 \mathrm{U} / \mathrm{l}$ in $\mathrm{M}+\mathrm{G}+$, before the tourniquet $(\mathrm{p}=0.118)$, $95.67 \mathrm{U} / \mathrm{l}$ during ( $\mathrm{p}$ $=0.001)$, and $135.443 \mathrm{U} / \mathrm{l}$ after emergence $(\mathrm{p}<0.00001)$.

The mean plasma concentration of GPX was $2.306 \mu \mathrm{g} / \mathrm{ml}$ in M0G0's. In M + $\mathrm{G}+$, it was $3.567 \mathrm{pg} / \mathrm{ml}$ before tourniquet $(\mathrm{p}=0.0001), 3.645 \mathrm{pg} / \mathrm{ml}$ during $(\mathrm{p}<$ $0.00001)$ and $3.694 \mathrm{pg} / \mathrm{ml}$ after release $(\mathrm{p}<0.00001)$.

Mean serum calcium was $2.879 \mathrm{mmol} / \mathrm{l}$ in M0G0's. Conversely, in $\mathrm{M}+\mathrm{G}+$, it was $3.00 \mathrm{mmol} / \mathrm{l}$ before tourniquet $(\mathrm{p}=0.683), 3.64 \mathrm{mmol} / \mathrm{l}$ during $(\mathrm{p}=0.035)$, and 3.892 after emergence $(p=0.012)$. In $M+G+$, mean serum potassium was $3.934 \mathrm{mmol} / \mathrm{l}$ before tourniquet placement $(\mathrm{p}=0.219), 4.757 \mathrm{mmol}$ during $(\mathrm{p}=$ $0.0006)$, and $5.322 \mathrm{mmol} / \mathrm{l}$ after tourniquet emergence $(\mathrm{p}<0.00001)$, versus $3.705 \mathrm{mmol} / \mathrm{l}$ in M0G0 (Table 3).

\subsection{Comparison of Plasma Concentrations of GPX, CPK, $\mathrm{Ca}^{2+}, \mathrm{K}^{+}$ \\ Taken in Patients with Myomectomy without Using Elastic \\ Tourniquet (M + G -), Compared with Control Women (M0G0)}

In $\mathrm{M}+\mathrm{G}-$, the mean plasma $\mathrm{CPK}$ concentration was $59.354 \mathrm{U} / \mathrm{l}$ before surgery, 91.270 U/l during $(\mathrm{p}=0.005)$, and $137.776 \mathrm{U} / \mathrm{l}$ after $(\mathrm{p}=0.0005)$, compared with $57.21 \mathrm{U} / 1$ at M0G0.

The mean plasma concentration of GPX in $\mathrm{M}+\mathrm{G}$ - was $3.255 \mu \mathrm{g} / \mathrm{ml}$ before surgery, $3.413 \mu \mathrm{g} / \mathrm{ml}$ during $(\mathrm{p}=0.008)$ and $3.632 \mu \mathrm{g} / \mathrm{ml}$ after $(\mathrm{p}=0.001)$. In M0G0, it was $2.306 \mathrm{pg} / \mathrm{ml}$.

Table 2. Comparison of plasma concentrations of GPX, CPK, $\mathrm{Ca}^{2+}, \mathrm{K}^{+}$of control women (M0G0) to women with unoperated myoma $(\mathrm{M}+\mathrm{G} 0)$.

\begin{tabular}{cccc}
\hline Markers & M0G0 & M + G0 & p \\
\hline CPK (U/l) & 57.208 & 71.640 & 0.118 \\
GPX (pg/ml) & 2.306 & 3.567 & $10^{-4 \star}$ \\
$\mathrm{Ca}^{2+}(\mathrm{mmol} / \mathrm{l})$ & 2.879 & 3.004 & 0.683 \\
$\mathrm{~K}^{+}(\mathrm{mmol} / \mathrm{l})$ & 3.705 & 3.934 & 0.219
\end{tabular}

${ }^{*} \mathrm{p}=0.0001$. 
Table 3. Comparison of plasma concentrations of GPX, CPK, $\mathrm{Ca}^{2+}, \mathrm{K}^{+}$obtained in patients with myomectomy using elastic tourniquet or ET $(M+G+)$ compared to control women (M0G0).

\begin{tabular}{|c|c|c|c|}
\hline Markers & MOG0 & $M+G+$ & $\mathrm{p}$ \\
\hline \multicolumn{4}{|l|}{ CPK (U/L) } \\
\hline Before using ET & 57.208 & 71.64 & 0.118 \\
\hline During using ET & & 95.665 & 0.001 \\
\hline After release ET & & 135.443 & $<10^{-5 x}$ \\
\hline \multicolumn{4}{|l|}{$\mathrm{GPX}(\mathrm{pg} / \mathrm{ml})$} \\
\hline Before using ET & 2.306 & 3.567 & $10^{-4 * *}$ \\
\hline During using ET & & 3.645 & $<10^{-5 *}$ \\
\hline After release ET & & 3.694 & $<10^{-5 x}$ \\
\hline \multicolumn{4}{|l|}{$\mathrm{Ca}^{2+}(\mathrm{mmol} / \mathrm{l})$} \\
\hline Before using ET & 2.879 & 3,000 & 0.683 \\
\hline During using ET & & 3,642 & 0.035 \\
\hline After release ET & & 3,892 & 0.012 \\
\hline \multicolumn{4}{|l|}{$\mathrm{K}^{+}(\mathrm{mmol} / \mathrm{l})$} \\
\hline Before using ET & 3.705 & 3.934 & 0.219 \\
\hline During using ET & & 4.757 & $0.6 \times 10^{-5 * * *}$ \\
\hline After release ET & & 5.322 & $<10^{-5 x}$ \\
\hline
\end{tabular}

${ }^{*} \mathrm{p}<0.00001 ;{ }^{* *} \mathrm{p}=0.0001 ;{ }^{* * *} \mathrm{p}=0.0006$.

Mean serum calcium was $2.879 \mathrm{mmol} / \mathrm{l}$ in M0G0, whereas it was in $\mathrm{M} 0+\mathrm{G}-$ before surgery $2.525 \mathrm{mmol} / \mathrm{l}(\mathrm{p}=0.109)$, while $3.068 \mathrm{mmol} / \mathrm{l}(\mathrm{p}=0.515)$ and after $3.148(\mathrm{p}=0.396)$.

Mean serum potassium was $3.705 \mathrm{mmol} / \mathrm{l}$ in M0G0's. In $\mathrm{M}+\mathrm{G}-$, it was 3.788 $\mathrm{mmol} / \mathrm{l}$ before surgery $(\mathrm{p}=0.557), 4.257 \mathrm{mmol} / \mathrm{l}$ during $(\mathrm{p}=0.023)$ and 5.075 $\mathrm{mmol} / \mathrm{l}$ after $(\mathrm{p}=0.0012)($ Table 4$)$.

3.5. Comparison of Plasma Concentrations of GPX, CPK, $\mathrm{Ca}^{2+}, \mathrm{K}^{+}$ Collected before, during and Fifteen Minutes after the Emergence of the Tourniquet in Patients with Myomectomy Using Elastic Tourniquet $(M+G+)$, Compared with Those of Women Operated on Myoma without Using Elastic Tourniquet $(\mathrm{M}+\mathrm{G}-)$

In the basal state, plasma CPK concentrations were $71.4 \mathrm{U} / \mathrm{l}$ in $\mathrm{M}+\mathrm{G}+$, compared to $59.354 \mathrm{U} / \mathrm{l}$ in $\mathrm{M}+\mathrm{G}-(\mathrm{p}=0.084)$. $95.665 \mathrm{U} / \mathrm{l}$ in $\mathrm{M}+\mathrm{G}+$, compared to $91.270 \mathrm{U} / \mathrm{l}$ in $\mathrm{M}+\mathrm{G}-$, five minutes after myoma ablation ( $\mathrm{p}=$ 0.462). They were $134.443 \mathrm{U} / \mathrm{L}$ fifteen minutes after the tourniquet release in $\mathrm{M}$ $+\mathrm{G}+$, compared with $137.776 \mathrm{U} / \mathrm{l}$ in $\mathrm{M}+\mathrm{G}-$, fifteen minutes after uterine suture $(\mathrm{p}=0.732)$. 
Table 4. Comparison of plasma concentrations of GPX, CPK, $\mathrm{Ca}^{2+}, \mathrm{K}^{+}$taken in patients with myomectomy without using elastic tourniquet $(M+G-)$, compared with control women (M0G0).

\begin{tabular}{cccc}
\hline Markers & M0G0 & M + G & p \\
\hline CPK (U/L) & & & 0.812 \\
Before surgery & 57.208 & 59.354 & 0.005 \\
During surgery & & 91.270 & $0.5 \times 10^{-5 *}$ \\
After surgery & & 137.776 & \\
GPX (pg/ml) & & 0.042 \\
Before surgery & 2.306 & 3.255 & 0.008 \\
During surgery & & 3.413 & 0.001 \\
After surgery & & 3.632 & \\
Ca ${ }^{2+}$ (mmol/l) & & & 0.109 \\
After surgery & 2.879 & 2.525 & 0.515 \\
During surgery & & 3.068 & 0.396 \\
After surgery & & 3.148 & 0.557 \\
$\mathrm{~K}^{+}$(mmol/l) & & 3.788 & 0.023 \\
Before surgery & & 4.257 & \\
During surgery & & 5.075 & \\
After surgery & & &
\end{tabular}

${ }^{*} \mathrm{p}=0.0005 ;{ }^{* *} \mathrm{p}=0.0012$

The average plasma concentrations of GPX were $3.567 \mu \mathrm{g} / \mathrm{ml}$ in $\mathrm{M}+\mathrm{G}+$ versus $3.255 \mu \mathrm{g} / \mathrm{ml}$ in $\mathrm{M}+\mathrm{G}$ - before surgery $(\mathrm{p}=0.321)$. During surgery, they were $3.645 \mu \mathrm{g} / \mathrm{ml}$ at $\mathrm{M}+\mathrm{G}+$, versus $3.413 \mathrm{pg} / \mathrm{ml}$ in $\mathrm{M}+\mathrm{G}-(\mathrm{p}=0.317)$. Fifteen minutes after emergence of ET in $\mathrm{M}+\mathrm{G}+$, these levels were $3.694 \mathrm{U} / \mathrm{l}$, as against $3.632 \mathrm{U} / \mathrm{l}$, fifteen minutes after the uterine suture in $\mathrm{M}+\mathrm{G}-(\mathrm{p}=0.001)$.

Plasma $\mathrm{Ca}^{2+}$ concentrations were $3 \mathrm{mmol} / \mathrm{l}$ in $\mathrm{M}+\mathrm{G}+$, compared to 2.525 $\mathrm{mmol} / \mathrm{l}$ in $\mathrm{M}+\mathrm{G}-(\mathrm{p}=0.171)$, prior to surgery. During surgery, they were $3.642 \mathrm{mmol} / \mathrm{l}$ in $\mathrm{M}+\mathrm{G}+$, against $3.060 \mathrm{mmol} / \mathrm{l}$ in $\mathrm{M}+\mathrm{G}-(\mathrm{p}=0.185)$. Fifteen minutes after the uterine suture, they were $3.892 \mathrm{mmol} / \mathrm{l}$ in the $\mathrm{M}+\mathrm{G}+$, versus $3.413 \mathrm{mmol} / \mathrm{l}$ in $\mathrm{M}+\mathrm{G}-(\mathrm{p}=0.073)$.

Mean kaliemias were $3.148 \mathrm{mmol} / \mathrm{l}$ in $\mathrm{M}+\mathrm{G}+$, compared to $3.148 \mathrm{mmol} / \mathrm{l}$ in $M+G-$, before surgery $(p=0.285)$. During surgery, they were $4.575 \mathrm{mmol} / \mathrm{l}$ in $\mathrm{M}+\mathrm{G}+$, versus $4.257 \mathrm{mmol} / \mathrm{l}$ in $\mathrm{M}+\mathrm{G}-(\mathrm{p}=0.010)$. After surgery, these concentrations were $5.322 \mathrm{mmol} / \mathrm{l}$ in $\mathrm{M}+\mathrm{G}+$, compared to $5.075 \mathrm{mmol} / \mathrm{l}$ in $\mathrm{M}$ $+\mathrm{G}-$ respectively $(\mathrm{p}=0.101)($ Table 5$)$.

\section{Discussion}

This work was initiated to study the variations in plasma concentrations of markers of ischemia $\left(\mathrm{CPK}, \mathrm{K}^{+}, \mathrm{Ca}^{2+}\right)$ and reperfusion (GPX) in patients operated 
Table 5. Comparison of plasma concentrations of GPX, CPK, $\mathrm{Ca}^{2+}, \mathrm{K}^{+}$collected before, during and fifteen minutes after the emergence of the tourniquet in patients with myomectomy using elastic tourniquet or ET $(M+G+)$, compared with those of women operated on myoma without using tourniquet $(\mathrm{M}+\mathrm{G}-)$.

\begin{tabular}{lccc}
\hline \multicolumn{1}{c}{ Markers } & $\mathrm{M}+\mathrm{G}+$ & $\mathrm{M}+\mathrm{G}$ & $\mathrm{p}$ \\
\hline $\mathrm{CPK}(\mathrm{U} / \mathrm{L})$ & & & 0.084 \\
Before surgery/using ET & 71.400 & 59.354 & 0.462 \\
During surgery/using ET & 95.665 & 91.270 & 0.732 \\
After surgery/using ET & 135.443 & 137.776 & \\
GPX (pg/ml) & & & 0.321 \\
Before surgery/using ET & 3.567 & 3.255 & 0.317 \\
During surgery/using ET & 3.645 & 3.413 & 0.001 \\
After surgery/using ET & 3.694 & 3.632 & \\
Ca ${ }^{2+}$ (mmol/l) & & & 0.171 \\
Before surgery/using ET & 3.000 & 2.525 & 0.185 \\
During surgery/using ET & 3.642 & 3.068 & 0.073 \\
After surgery/using ET & 3.892 & 3.148 & \\
$\mathrm{~K}^{+}$(mmol/l) & & & 0.285 \\
Before surgery/using ET & 3.934 & 3.788 & 0.010 \\
During surgery/using ET & 4.757 & 4.257 & 0.101 \\
After surgery/using ET & 5.322 & &
\end{tabular}

on uterine myoma with use of the tourniquet, whose duration of pose did not exceed 90 minutes. To do this, we conducted a prospective case-control study, during which we encountered several constraints.

One of the biggest difficulties was the refusal to participate, especially since it concerned almost $40 \%$ of the total population and more than half of $M+G+$ women.

The second problem we faced was the lack of routine dosing of GPX [42] [43]. As a result, we used the recruitment of a population of control women (M0G0). The plasma levels of the markers obtained in these individuals thus allowed us to have a reference value or control concentration of GPX [42] [43].

At the same time, comparing this control concentration to that found in $\mathrm{M}+$ G0 women gave us the opportunity to identify all women with unoperated myomas who had elevated plasma levels of IR markers. Indeed, in the literature, a direct link has been found between myomatous pathology and oxidative stress phenomena, at least from the physiological and systemic point of view [45] [46]. That is to say that in physiological conditions, in women with asymptomatic myomas, the antioxidant and prooxidant status would be imbalanced, this at the expense of the second. This implies that in the basal state, a rise in GPX levels is observable in people with myomas. 
Finally, the comparison of plasma levels of GPX and CPK between the two groups of women operated on myomas with $(M+G+)$ or without elastic tourniquet $(M+G-)$, should lead us to confirm or not, if the changes in concentrations Plasma levels of these markers were mainly due to the use of elastic tourniquet (within the time limits set by our protocol), but not to the myomectomy itself, nor to the incision or the uterine suture. IR manifestations and oxidative stress have actually been noted during some types of abdominal surgeries and myomectomies [47] [48] [49]. In these studies, the assay techniques used were generally enzyme immunoassays, while GPX was one of the most frequently determined biomarkers [47] [48] [49] [50].

Finally, all these methodological constraints resulted in a significant drop in sample size. However, despite these limitations, our results show that, like pneumatic tourniquet [12] [13] [14] [15] [16] [51], elastic tourniquet is not the cause of the increase in plasma $I / R$ markers observed in women $M+G+$. Therefore, this elevation is probably related to the surgical procedure. This situation explains the absence of a significant difference in marker rates between the two groups of women operated $(M+G+$ and $M+G-)$, whereas there are significant variations within each group, but also with respect to to those of the M0G0 controls. Moreover, these data suggest that systemic manifestations of IR are not observed during exposure times of elastic tourniquet of less than 90 minutes.

\subsection{Comparison of Plasma Concentrations of GPX, CPK, $\mathrm{Ca}^{2+}, \mathrm{K}^{+}$of Control Women (M0G0), of Women with Unoperated Myoma (M + G0)}

At the end of our study, no statistically significant difference was found between the plasma concentrations of ischemia markers $\left(\mathrm{CPK}, \mathrm{K}+, \mathrm{Ca}^{2+}\right.$ found in controls (M0G0) and those of women with unoperated myomas $(\mathrm{M}+\mathrm{G} 0)$. These results show that the plasma levels of ischemia markers obtained in women with non-operated myoma $(M+G-)$ are not different from those of healthy women (M0G0).

Our data thus suggest that the myomas in themselves probably do not have systemic detectable proischemic activity, despite intense in situ proliferative activity, previously observed by Cibiera, Guo, Zheng, et al. [52] [53] [54] [55]. However, concerning the plasma level of GPX (marker of reperfusion), there was a significant variation between the two groups. In this case, it could be an asymptomatic necrosis of myomas in a previous period, but recent in our study. Indeed, in the literature, high levels of GPX have been observed in women with myomas, and this elevation would be dependent on the hormonal cycle [45] [46] [48]. A positive correlation existed between the GPX level and the ratio estrogen/progesterone at the plasma level. In contrast, there was a negative correlation between FSH concentrations and intra-myopathic GPX levels. According to the authors, the systemic cyclic hormonal variations within the 
myomatous tissue would be at the origin of oxidative stress and could partly explain the fact that this pathology is uncommon in postmenopausal women [45] [46].

Thus, despite the intense local proliferative and oxidative activity of uterine myomas, our data allow us to consider the concentrations of IR markers obtained in M0G0's as a control or reference concentration [42] [43] [50].

\subsection{Comparison of Plasma Concentrations of GPX, CPK, $\mathrm{Ca}^{2+}, \mathrm{K}^{+}$ Collected before, during, and Fifteen Minutes after Uterine Suture in Patients with Tournaments of Myoma without Using Elastic Tourniquet (M + G-), Compared with Control Women (M0G0)}

A statistically significant difference was found between the plasma concentrations of the markers of ischemia (CPK, $\mathrm{K}+$ ) and reperfusion (GPX) of the controls (M0G0) and those measured during the ablation of the myomas and after the suture of uterus without tourniquet in $\mathrm{M}+\mathrm{G}-$ women. CPK concentrations of $M+G-$ women were less than once normal during uterine suture $(p=0.001)$, and more than 2 times normal 15 minutes after $(p=0.0005)$. Those of GPX were 1.58 times the control value during uterine suture $(\mathrm{p}=0.008)$, and 1.6 times that of controls, 15 minutes later $(\mathrm{p}=0.001)$. The relationship between $\mathrm{I} / \mathrm{R}$ and surgical intervention on the one hand, and IR without removal of myoma without tourniquet on the other hand, have been widely described [9] [28] [29] [35] [36] [39] [47] [49] [56] [57] Indeed, with respect to uterine surgery without tourniquet use, regardless of the technique (laparoscopy/laparotomy), it has been shown to be responsible for systemic I/R phenomena, due to surgical act [47] [49] [56] [57]. In this case, the elevation of the markers observed in $M+G$ - could be explained by incisions and parietal and uterine sutures. In the same way, another explanation would be rather related to the ablation of the myomas proper.

A study by Farimani et al., which examined the expression of markers of oxidative stress after myomectomy, found elevated levels of GPX3 and glycodelin in the myometrium, up to 3 months after surgery, in women who received a myomectomy without tourniquet. According to the latter, the myomectomy would lead to an expression of GPX, so oxidative stress phenomena in relation to the implantation zone of the egg. This mechanism could be involved in the infertility observed in these patients [48].

As a result, compared with plasma reference levels (control values), plasma concentrations of IR markers are elevated in $M+G-$ during the surgical period. Thus, the classical surgical procedure (incision, then uterine and parietal suture), constantly practiced during this type of intervention would be the main cause of this increase [47] [49] [56] [57]. However, despite the fact that this is difficult to demonstrate in practice, the intra uterine expression of GPX evoked by Farimani et al. during the ablation of myomas, taken in isolation, could promote a secondary elevation of plasma GPX levels [48]. 


\subsection{Comparison of Plasma Concentrations of GPX, CPK, $\mathrm{Ca}^{2+}, \mathrm{K}^{+}$ Taken before, during and Fifteen Minutes after the Emergence of the Tourniquet in Patients with Myomectomy Using Elastic Tourniquet $(M+G+)$ Compared with Controls (M0G0)}

Compared with M0G0 women, the plasma concentrations of I/R markers were not significantly different from those found in $M+G+$ women before surgery $(p=0.118)$. Conversely, those obtained during the pose and fifteen minutes after the lifting of the elastic tourniquet were not only high compared to the control values, but were still significantly higher after the lifting of the elastic tourniquet with respect to the exposure period. These data assume that surgeries requiring any temporary arrest of the arterial circulatory system, such as tourniquet use, lead to ischemia reperfusion and apoptosis [2] [7] [12] [13] [14] [15] [16] [29] [30] [31] [32] [34] [58]. This IR would itself be responsible for an increase in intracellular calcium mediated by the $\mathrm{Ca}^{2+}$ complex and the 1,4,5 Inositol triphophate1/Ryanodine 1 (IP3R1/RYR1) receptors [34]. the difference in concentration noted between the duration of tourniquet application and that of relapse corroborates the results of several studies [12] [13] [14] [15] [16] [29] [30] [31] [32], and thus suggests greater muscle suffering during reperfusion [3] [4] [6] [13] [14] [15] [16] [32] [32] [35] [36]. However, our results do not allow us to specify whether this elevation is related exclusively to the use of the withers [7] [27] [31] [33] [34] [58], removal of myomas [48], and/or incision followed by uterine and parietal suture [47] [49] [56] [57].

To compare the plasma concentrations of GPX, $\mathrm{CPK}, \mathrm{Ca}^{2+}, \mathrm{K}^{+}$collected before, during and fifteen minutes after the emergence of the elastic tourniquet in patients with tournaments of tourniquet-shaped myoma $(M+G+)$, compared to patients with myocardial surgery without tourniquet $(M+G-)$.

Before surgery, the plasma concentrations of I/R markers of women operated without tourniquet-free myoma $(M+G-)$ were not significantly different from those operated for myoma using tourniquet $(M+G-)$ This result suggests that myomas are probably not in themselves responsible for systemic I/R phenomena, despite prooxidative and inflammatory intra-myomatous activity described by contemporary studies [45] [46] [52] [53] [54]. Thus, Snezana and et al., as well as Santulli and et al., noted overexpression of prooxidant species in myomatous tissue correlated with hormonal variation during the menstrual cycle in women still sexually active [45] [46].

In the same way, during the entire duration of the elastic tourniquet in women $\mathrm{M}+\mathrm{G}+$ (time corresponding to the ligation of the arteries, the uterine incision and the removal of the myomas in the subjects $M+G+$ ), the plasma levels markers obtained were not different from those of patients operated for myomas without tourniquet (time corresponding to uterine incision and ablation of myomas without tourniquet in $M+G-$ ), but were nevertheless higher than the control concentrations (M0G0). Several explanations of this result are possible. 
With respect to GPX and CPK plasma assay techniques, although those used in the present investigation have few limitations, their system-level sensitivities to IR are limited. is not absolute [42] [43] [50]. To do this, a plasma assay of markers correlated with an immunohistochemical study would be more interesting [48] [49].

Another explanation is the existence of a network of vascular supply at the uterine level and around the fibroid [59]. This important vascular network could improve circulation during arterial ligation, thus decreasing the production and accumulation of free radicals and other molecules from tissue pain. According to several authors, this type of vascularization could explain the tolerance of the uterus with respect to ischemia and paradoxically the destruction of certain myomas observed after myomectomies by arterial ligation [29]-[39] [58] [59] [60].

A third reason would be related to the actual surgical procedure. Thus, the elevation of markers noted in women who had undergone a myomectomy $(\mathrm{M}+$ $\mathrm{G}+/ \mathrm{M}+\mathrm{G}-$ ) would be mainly due to the surgical act, that is to say to the tissue damage linked to the incision parietal and uterine, as well as ablation of myomas. Several studies have shown that abdominal surgery is responsible for tissue and systemic ischemia and inflammation [47] [49] [56] [57]. Oksuzoglu and et al., comparing plasma levels of CPK and interleukin-6 (IL6) in different types of uterine surgery, found higher levels of these markers during uterine abdominal versus laparoscopic surgery [57]. Al-Khyatt and et al., for their part, observed ischemia phenomena during laparoscopic intestinal surgery [56].

At the end of this investigation, the average tourniquet duration was $51.56 \pm$ 14.12 minutes, with extremes of 30 and 88 minutes. Apart from myocardial ischemia, which is usually established in less than an hour [1] [2] [8], in the majority of studies concerning the phenomena of tissue ischemia in general, and more specifically that of origin these lesions occur downstream and beyond the $2^{\text {nd }}$ hour during a circulatory interruption upstream [7] [12] [13] [14] [15] [16] [32] [34] [37] [39] [51]. In other words, the duration of tourniquet less than 90 minutes could also be a factor explaining the absence of significant variation in plasma marker levels between groups of women $M+G+$ and $M+G-$, despite their elevation within each of the two groups. Indeed, the phenomena of ischemia were observed both in animals than in humans, only during periods of arterial occlusion exceeding $1 \mathrm{~h} 30$ minutes. In orthopedics, in animals, inflating times greater than 2 hours would be responsible for sometimes irreversible muscle damage, despite the duration of reperfusion of more than 3 hours [12] [13] [14] [15]. One of the mechanisms involved is a progressive decrease in super oxide dismutase with mitochondrial dysfunction. In humans, according to Omar [16], Oragui [15], and Van der Spuy and et al. [51], tourniquet exposure times exceeding 2 hours are responsible for systemic ischemic phenomena. In the opinion of the same authors, the plasma marker levels of IR.

On a human scale, these lesions appear at the same time and would have repercussions on the myometrium, the myoma, the ovarian function, as well as 
the long-term fertility [27] [28] [29] [30] [31] [35] [36] [39] [40]. In addition, the human uterus is more tolerant to cold ischemia than the warm one [36]. In the case of myomectomies performed in women, a Nigerian [22] and a Bulgarian [61] study respectively noted a correlation between the post-operative complications of abdominal myomectomies and the exposure times of elastic tourniquet greater than 3 hours. With respect to myomectomies, Banus and al, during myomectomies performed by arterial embolization, also found elevated plasma levels of ischemia markers at the end of the $3^{\text {rd }}$ hour after embolization [39]. Studies found muscle ischemia lesions on average beyond the $2^{\text {nd }}$ hour. It is this situation that is likely to advocate tourniquet delay or any interruption of arterial circulation not exceeding 120 minutes during this type of surgery [18] [20] [23] [24] [59].

During our investigation, more than half of myoma operated women $(M+G$ + and $M+G-)$ had more than 10 myomas, ranging in size from 18.26 to 23.11 $\mathrm{mm}$.

The number, but also the size and locations of the myomas could also be elements that can influence the systemic expression of ischemia generated in situ by the effect of the elastic tourniquet. According to some authors, these factors considerably modify the duration of myomectomies because of their impact on the ablation of the myomas themselves [17] [22] [24] [26] [40] [59] [61]. That the placement of GE not more than 90 minutes is not likely to be the cause of the increased biomarkers of ischemia observed in $M+G+$ women at the systemic level. In this case, despite other factors such as the characteristics of the myoma and the system of uterine vascular supply that can influence the kinetics of these markers, this result suggests that this elevation is exclusively secondary to the actual surgical activity. .

After the release of the tourniquet (the time corresponding to the end of myoma ablation and suture of the uterus in $M+G+$, and at the end of the uterine suture in $M+G-$ ), plasma concentrations markers of ischemia (calcium, CPK and potassium) and reperfusion (GPX) were higher compared to control values (M0G0). However, comparing the levels of markers obtained in $\mathrm{M}$ $+G+$ to those of $M+G-$, it appears that those of ischemia did not vary between the two groups, whereas those of GPX were significantly different ( $\mathrm{p}=$ 0.001). Compared to the basal state (control value), these results show that the plasma concentrations of ischemia markers are increased in women operated on myomas $(M+G+$ and $M+G-)$, but without however, differ between these two groups. Physiopathologically corresponding tourniquet emergence from IR to the reperfusion phase, the low specificity of serum calcium, potassium, and CPK with respect to reperfusion could be an explanation for this result [1]-[8] [10] [13] [15] [50] [51] [58]. According to Yang and et al., under hypoxic conditions, such as those encountered during ischemia by uterine arterial occlusion, calcium would be involved in cellular apoptosis phenomena via IP3R1/RYR1 receptors [34]. 
Similarly, the existence of uterine vascular replacement, associated with tourniquet durations not exceeding $1 \mathrm{~h} 30$ minutes during our investigation, would also be another reason [59]. Continuous or even partial perfusion, would favor a progressive decrease in the plasma concentration of the markers before the recirculation process secondary to the lifting of the tourniquet [1]-[7] [12] [13] [14] [32] [51] [58] [62].

Finally, these data support the idea that surgery is a process responsible for ischemic phenomena [3] [47] [49] [56] [57]. Moreover, in comparison with the control values, they assume that the variation noted is not due to the relaxation of the withers, but rather to the ischemia related to the surgical incisions.

There was a statistically significant difference, despite a slight variation in GPX plasma concentrations between $\mathrm{M}+\mathrm{G}+$ and $\mathrm{M}+\mathrm{G}-$ (3.694 versus 3.632, $\mathrm{p}=0.001$ ), after the lifting of the elastic tourniquet (time corresponding to the end of the removal of myomas and suture of the uterus in $M+G+$, and at the end of uterine suture in $M+G-$ ). The sensitivity of GPX to reperfusion is well established [42] [43] [50], the incomplete uterine ischemia caused by the existence of the vascular supply [59] strongly solicited during uterine surgeries. Performed under arterial occlusion, could explain this result once again [29] [30] [31] [35] [36]. According to Byron and et al. [14], the relaxation of the tourniquet performed on the lower limb of a rat is immediately accompanied by an overproduction of the biomarkers of the IR. In this case, we can say that there is a phenomenon of reperfusion during the myomectomies under tourniquet, but it is of lesser degree, probably due to complex anastomotic intrauterine and peri-myomatous vasculature previously evoked by Nassif and et al. [59].

To a lesser degree, the tourniquetation times chosen in this study, together with the particular vascularization of the uterus, may also justify the data obtained. In the literature, most of the work dealing with this aspect of the subject is of an experimental nature.

Thus, in macaques, Kisu and et al. [32], as well as Adachi and et al. [62], noted high levels of reperfusion markers only at the end of the $1^{\text {st }}$ and $3^{\text {rd }}$ hours respectively after the arterial occlusion was removed. Tsompos and al. Looking for markers of muscle pain after half an hour in rats, had obtained similar data [32]. In humans, a study by Banu et al, in women with myomas uterine patients, had elevated plasma concentrations of markers of ischemia and inflammation only 24 hours after embolization of the uterine arterial occlusion, but did not specify the surgical or emboligenic origin of this increase [39]. As a result, this result shows that the lifting of the elastic tourniquet is not the cause of the increase in plasma $I / R$ markers found in $M+G+$ women. Moreover, he suggests that the variations of the markers observed during the various surgical stages within each of the two groups of women operated $(M+G+/ M+G-)$ compared to those of the controls (M0G0) are due essentially to the surgical procedure, ie the intensity of the lesion process linked to the operative procedure (parietal and uterine incision, ablation of the myomas, parietal suture, then uterine) which depends in part on the operating time. 


\section{Conclusion}

The plasmatic concentration of ischemia $\left(\mathrm{CPK}, \mathrm{K}^{+}\right)$and reperfusion ( $\left.\mathrm{GPX}, \mathrm{Ca}^{2+}\right)$ biomarkers does not differ between $M+G+$ and $M+G-$, but is elevated relatively to controls (M0G0), but also to $M+$ G0's group. These results show that, for exposure times not exceeding 90 minutes, the elastic tourniquet is probably not the cause of the increase in plasma $I / R$ markers observed in $M+G$ + women. Moreover, these data suggest that the variations of the markers observed during the different surgical stages within each of the two groups of women $M+G+$ and $M+G-$ compared to those of the controls (M0G0) and unoperated myomas $(\mathrm{M}+\mathrm{G} 0)$ are due essentially to the surgical act.

\section{Conflicts of Interest}

The authors do not declare any conflict of interest in relation to this investigation.

\section{References}

[1] Debnath, J. and Nath, L.K. (2014) A Review on Pathophysiology of Ischemic Reperfusion Injury of Heart and Ameliorating Role of Flavonoids and Polyphenols. Journal of Medicinal Plant Research, 8, 607-614. https://doi.org/10.5897/JMPR2014.5360

[2] Wang, H.L., Cao, C.Y. and Hui, L.Q. (2016) A Study of Myocardial Ischemia Model Induced by Left Coronary Artery Ligation in Rats. World Journal of Cardiovascular Diseases, 6, 133-142. https://doi.org/10.4236/wjcd.2016.65014

[3] Hanouz, J.L., Gerard, J.L. and Plaud, B. (2009) Ischémie-Reperfusion. In: Martin, C., Riou, B. and Vallet, B., Eds., Physiologie Humaine Appliquée, 2éd, Arnette wolterskluwer France, Paris, 217-227.

[4] Neri, M., Riezzo, I., Pascale, N., Pomara, C. and Turillazzi, E. (2017). Ischemia/Reperfusion Injury Following Acute Myocardial Infarction: A Critical Issue for Clinicians and Forensic Pathologists. Mediators of Inflammation, 2017, 1-14. https://doi.org/10.1155/2017/7018393

[5] Fernández-Jiménez, R., García-Prieto, J., Sánchez-González, J., et al. (2015) Pathophysiology Underlying the Bimodal Edema Phenomenon after Myocardial Ischemia/Reperfusion. Journal of the American College of Cardiology, 66, 816-828. https://doi.org/10.1016/j.jacc.2015.06.023

[6] Feng, H.B., Wang, H.L., Zhao, Y., Zheng, Z.N. and Jin, S. (2016) Gradual Clamping Reduced Ischemia-Reperfusion Injury in an Isolated Rat Heart Model. World Journal of Cardiovascular Surgery, 6, 79-86. https://doi.org/10.4236/wjcs.2016.66013

[7] Yunus, O.A., Serap, A., Sadik, S., Zafer, K. and Ozlem, B.O. (2015) Remifentanil Protects Uterus against Ischemia-Reperfusion Injury in Rats. Acta Chirurgica Brasileira, 30, 756-761. https://doi.org/10.1590/S0102-865020150110000006

[8] Coquerel, D. and Tamion, F. (2011) Ischémie-Reperfusion Myocardique-Aspects Physiopathologiques. Journal de Réanimation, 20, 267-273.

https://doi.org/10.1007/s13546-010-0102-5

[9] Hashimoto, N. (2015) Protective Effect of Ischemic Preconditioning on Hepatic Ischemia-Reperfusion Injury in Rats. Open Access Library Journal, 2, e1306-e1312. https://doi.org/10.4236/oalib.1101306 
[10] Elsharawy, M.A., Elsaid, A. and Elsharawi, I. (2014) Reperfusion of Delayed Acute Occlusive Limb Ischemia. Is It Worthwhile. World Journal of Cardiovascular Diseases, 4, 580-585. https://doi.org/10.4236/wjcd.2014.412070

[11] Zhang, D., Lou, W., Chen, G., Yin, X. and Gu, J. (2013) Endovascular Treatment Options of Acute Limb Ischemia. International Journal of Medical Physics, Clinical Engineering and Radiation Oncology, 2, 39-43. https://doi.org/10.4236/ijmpcero.2013.21006

[12] Estèbe, J.P., Davies, J.M. and Richebe, P. (2011) The Pneumatic Tourniquet. Mechanical, Ischaemia-Reperfusion and Systemic Effects. European Journal of Anaesthesiology, 28, 404-411. https://doi.org/10.1097/EJA.0b013e328346d5a9

[13] Tran, T.P., Huiyin, Tu., Iraklis, I. and Pipinos, B. (2011) Tourniquet-Induced Acute Ischemia-Reperfusion Injury in Mouse Skeletal Muscles Involvement of Superoxide. European Journal of Pharmacology, 650, 328-334. https://doi.org/10.1016/j.ejphar.2010.10.037

[14] Byron, E., Efstathios, K., Marina, P., Anastasios, G., Christodoulou, et al. (2012) Cuff Width Increases the Serum Biochemical Markers of Tourniquet-Induced Skeletal Muscle Ischemia in Rabbits. Science Journal, 35, e1245-e1250.

[15] Oragui, E., Parsons, A., White, T., Longo, U.G. and Khan, W.S. (2011) Tourniquet Use in Upper Limb Surgery. Hand, 6, 165-173. https://doi.org/10.1007/s11552-010-9312-6

[16] Omar, H., Elhamid, B.A., Rady, A. and Khaled, S. (2017) The Effect of Different Regional Blocks Combined FemoralSciatic, Spinal and Epidural Blocks on the Different Side Effects of Arterial Tourniquet in Patients Undergoing Lower Limb Orthopedic Surgeries. Open Journal of Anesthesiology, 7, 88-97. https://doi.org/10.4236/ojanes.2017.74009

[17] Ai, R.A., Yapca, O.E. and Gumusburun, N. (2017) A Randomized Trial Comparing Triple versus Single Uterine Tourniquet in Open Myomectomy. Gynecologic and Obstetric Investigation, 82, 547-552. https://doi.org/10.1159/000468932

[18] Parker, W.H. and Sharp, T.H. (2017) Technics to Reduce Blood Loss during Abdominal or Laparoscopic Myomectomy. https://uptodate.com

[19] Kongnyuy, E.J. and Wiysonge, C.S. (2014) Interventions to Reduce Haemorrhage during Myomectomy for Fibroid. Cochrane Database of Systematic Reviews, No. 11, CD005355. http://www.Cochrane.com https://doi.org/10.1002/14651858.CD005355.pub5

[20] Vilos, G.A. and Allaire, C. (2015) The Management of Uterine Leiomyomas. Journal of Obstetrics and Gynaecology Canada, 37, 157-178. https://doi.org/10.1016/S1701-2163(15)30338-8

[21] Taylor, A., Sharma, M. and Tsirkas, P. (2005) Reducing Blood Loss at Open Myomectomy Using Triple Tourniquets. Arandomised Controlled Trial. BJOG, 112, 340-345. https://doi.org/10.1111/j.1471-0528.2004.00430.x

[22] Adesina, K.T., Owolabi, B.O. and Raji, H.O. (2017) Abdominal Myomectomy. A Retrospective Review of Determinants and Outcomes of Complications at the University of Ilorin Teaching Hospital, Ilorin, Nigeria. Malawi Medical Journal, 29, 38-42. https://doi.org/10.4314/mmj.v29i1.8

[23] Lansac, J. and Descamps, P. (2011) La pratique chirurgicale en gynécologie obstétrique. In: Carlan, L., Bourlier, P. and Brétagnol, F., Eds., Chirurgie par voie abdomidale, 3ème Edition, Elsevier Masson, Paris, 142-148.

[24] Pundir, J., Walawalkar, R., Seshadri, S., Khalaf, Y. and El-Toukhy, T. (2013) Perioperative Morbidity Associated with Abdominal Myomectomy Compared with 
Total Abdominal Hysterectomy for Uterine Fibroids. Journal of Obstetrics and Gynaecology, 33, 655-662. https://doi.org/10.3109/01443615.2013.816661

[25] Ikechebelu, J.I., Ezeama, C.O. and Obiechina, N.J. (2010) The Use of Tourniquet to Reduce Blood Loss at Myomectomy. Nigerian Journal of Clinical Practice, 13, 154-158.

[26] Thalamkandathil, N. (2016) Laparoscopic Myomectomy-A Three Year Experience. International Journal of Reproduction, Contraception, Obstetrics and Gynecology, 5, 3560-3562. https://doi.org/10.18203/2320-1770.ijrcog20163444

[27] Migahed, L., Himaya, E. and Antaki, R. (2014) Variation of Anti-Mullerian Hormone Levels Following Myomectomy by Laparotomy. Fertility and Sterility, 102, e299. https://doi.org/10.1016/j.fertnstert.2014.07.1018

[28] Balsak, D. (2015) Effects of Melatonin on Ischemia-Reperfusion Injury in Rat Ovary. Histopathologic and Immunohisto Chemical Study. Open Journal of Obstetrics and Gynecology, 5, 639-645. https://doi.org/10.4236/ojog.2015.511090

[29] Lee, C., Chang, C.C. and Kuo, Y.-T. (2005) Color Doppler Evaluation of Blood Flow Changes in Leiomyomas after Utérine Artery Ligation. International Journal of Gynecology \& Obstetrics, 90, 44-45. https://doi.org/10.1016/j.ijgo.2005.02.024

[30] Kun-Min, C., Ming-Jer, C., Ming-Huei, L., Yuan-Der, H. and Chin-San, C. (2012) Fertility and Pregnancy Outcomes after Uterine Artery Occlusion with or without Myomectomy. Journal of Obstetrics and Gynaecology, 51, 331-335.

[31] Lin, H.M. (2006) Comparaison of Clinical Outcomes and Spectral Doppler Indice of Uterin and Ovarian Stromal Arteries in Women Undergoing Myomectomy with or without Hypogastrique Arterial Ligation. Ultrasound in Obstetrics \& Gynecology, 28, 813-836.

[32] Kisu, I., Umene, K., Adachi, M., Emoto, K., Nogami, Y., et al. (2017) Allowable Warm Ischemic Time and Morphological and Biochemical Changes in Uterine Ischemia/Reperfusion Injury in Cynomolgus Macaque: A Basic Study for Uterus Transplantation. Human Reproduction, 32, 2026-2035.

https://doi.org/10.1093/humrep/dex250

[33] Gauthier, T., Piver, P., Marquet, P., Couquet, C. and Aubard, Y. (2013) Transplantation utérine. Expérimentations animales. mt Médecine de la Reproduction. Gynécologie Endocrinologie, 15, 157-164.

[34] Yang, W., Cheng, Z. and Dai, H. (2014) Calcium Concentration Response to Uterine Ischemia. A Comparison of Uterine Fibroid Cells and Adjacent Normal Myometrial Cells. European Journal Of Obstetrics Gynecology And Reproductive Biology, 174, 123-127. https://doi.org/10.1016/j.ejogrb.2013.12.013

[35] Scheurig-Muenkler, C., Wagner, M., Franiel, T., Hamm, B. and Kroencke, T.J. (2010) Effect of Uterine Artery Embolization on Uterine and Leiomyoma Perfusion: Evidence of Transient Myometrial Ischemia on Magnetic Resonance Imaging. Journal of Vascular and Interventional Radiology, 21, 1347-1353. https://doi.org/10.1016/j.jvir.2010.05.008

[36] Cheng, Z.P., Tao, X., Gong, J., Dai, H. and Hu, L.P. (2009) Early-Stage Morphological Observations of Myoma and Myometrium after Laparoscopic Uterine Artery Occlusion Treatment. European Journal of Obstetrics Gynecology and Reproductive Biology, 145, 113-116. https://doi.org/10.1016/j.ejogrb.2009.03.027

[37] Brännström, M. and Wranning, C.A. (2010) Experimental Uterus Transplantation. Human Reproduction Update, 16, 329-345.

https://doi.org/10.1093/humupd/dmp049 
[38] Rakesh, S., Meenakshi, S. and Chaitali, M. (2011) Laparoscopic Myomectomy Whith Uterine Artery Ligation. Review Article and Comparative Analysis. Journal of Gynecological Endoscopy and Surgery, 2, 3-10.

[39] Banu, N.S., Gaze, D.C., Bruce, H., Collinson, P.O., Belli, A.M., et al. (2007) Markers of Muscle Ischemia, Necrosis, and Inflammation Following Uterine Artery Embolization in the Treatment of Symptomatic Uterine Fibroids. American Journal of Obstetrics and Gynecology, 196, 213-215.

[40] Shue, S., Radeva, M. and Falcone, T. (2018) Comparison of Long-Term Fertility Outcomes after Myomectomy. Relationship with Number of Myomas Removed. Journal of Minimally Invasive Gynecology, 25, 1002-1008.

[41] World Medical Association (2013) Declaration of Helsinki. Ethical Principals for Medical Research Involving Human Being Subjects. Helsinki.

http://www.wma.net/fr/

[42] Dieusaert, P. (2015) Guide pratique des analyses médicales. 6ème Edition, Maloine France, Paris, $1573 \mathrm{p}$.

[43] Elabsciences. http://www.elabscience.com/

[44] American Society of Anesthesiology and Canadian Anesthesiology Society (2018) Guidelines to the Practice of Anesthesia. Canadian Journal of Anesthesia, 65, 76-104.

[45] Snežana, P., Todorović, A., Stojiljković, V., Gavrilović, L., Popović, N., et al. (2015) Antioxidant Status in Women with Uterine Leiomyoma Relation with Sex Hormones. Anais da academia brasileira de ciências, 87, 1771-1782.

[46] Santulli, P., Borghese, B., Lemaréchal, H., Leconte, M., Millischer, A.E., et al. (2013) Increased Serum Oxidative Stress Markers in Women with Uterine Leiomyoma. PLOS ONE, 8, e72069.

[47] Arsalani-Zadeh, R., Ullah, S., Khan, S. and Macfie, J. (2011) Oxydative Stress in Laparoscopic versus Open Abdominal Surgery. Systematic Review. Journal of Surgical Research, 169, 59-68. https://doi.org/10.1016/j.jss.2011.01.038

[48] Farimani Sanoee, M., Alizamir, T., Faramarzi, S., Saidijam, M., Yadegarazari, R., et al. (2014) Effect of Myomectomy on Endometrial Glutathione Peroxidase 3 (GPx3) and Glycodelin mRNA Expression at the Time of the Implantation Window. Iranian Biomedical Journal, 18, 60-66.

[49] Fan, Z., Lu, J.-M., Yan, J.-J. and Gong, H. (2017) Effects of Dexmedetomidine on Inflammatory Response and Oxidative Stress in Laparoscopic Hysterectomy Patients. Journal of Hainan Medical University, 23, 57-60.

[50] Marrocco, I., Altieri, F. and Peluso, I. (2017) Measurement and Clinical Significance of Biomarkers of Oxidative Stress in Humans. Oxidative Medicine and Cellular Longevity, 2017, Article ID: 6501046.

[51] Van der Spuy, L. (2012) Complications of the Arterial Tourniquet. Southern African Journal of Anaesthesia and Analgesia, 18, 14-18.

[52] Cibiera, M., Włodarczyk, M., Wrzosek, M., Męczekalski, B., Nowicka, G., et al. (2017) Role of Transforming Growth Factor $\beta$ in Uterine Fibroid Biology. International Journal of Molecular Sciences, 18, e2435.

[53] Guo, J., Zheng, L., Chen, L., Luo, N., Yang, W., et al. (2015) Lipopolysaccharide Activated TLR4/NF- $\kappa$ B Signaling Pathway of Fibroblasts from Uterine Fibroids. International Journal of Clinical and Experimental Pathology, 8, 10014-10025.

[54] Zheng, F., Feng, C., Isabell, G.E. and Ewelina, B. (2014) Stromal Fibroblast Activation and Uterine Fibroids. Oncology Letters, 8, 479-486. 
https://doi.org/10.3892/ol.2014.2225

[55] Wu, R., Feng, J., Yang, Y., Dai, C., Lu, A., et al. (2017) Significance of Serum Total Oxidant/Antioxidant Status in Patients with Colorectal Cancer. PLOS ONE, 12, e0170003.

[56] Al-Khyatt, W., Thomas, J.D., Humes, D.J. and Lobo, D.N. (2013) Intestinal Ischemia Following Laparoscopic Surgery. A Case Series. Journal of Medical Case Reports, 7, 1-25. https://doi.org/10.1186/1752-1947-7-25

[57] Oksuzoglu, A. (2015) Comparison of Tissue Trauma after Abdominal, Vaginal and Total Laparoscopic Hysterectomy. Ginekologia Polska, 86, 268-273. https://doi.org/10.17772/gp/2072

[58] Tsompos, C., Panoulis, C., Toutouzas, K., Triantafyllou, A., Zografos, G., et al. (2016) The Effect of the Antioxidant Drug "U-74389g" on Uterus Congestion during Ischemia Reperfusion Injury in Rats. Journal of Reproductive Medicine, Gynaecology \& Obstetrics, 1, 001.

[59] Nassif, J. (2009) Traitement opératoire des fibromes utérins. mt Médecine de la Reproduction, Gynécologie Endocrinologie, 11, 164-169.

[60] De Bruijn, A.M., Lohle, P.N., Huirne, J.A., De Vries, J., Twisk, M., QUESTA-Trial Group, et al. (2018) Uterine Artery Embolization versus Hysterectomy in the Treatment of Symptomatic Adenomyosis. Protocol for the Randomized QUESTA Trial. JMIR Research Protocols, 7, e47-e53.

[61] Bechev, B. and Magunska, N. (2014) Factors Affecting Duration of the Laparoscopic Myomectomy. Akusherstvo i Ginekologiia, 53, 21-25.

[62] Adachi, M., Kisu, I., Nagai, T., Emoto, K., Banno, K., et al. (2016) Evaluation of Allowable Time and Histopathological Changes in Warm Ischemia of the Uterus in Cynomolgus Monkey as a Model for Uterus Transplantation. Acta Obstetricia et Gynecologica Scandinavica, 95, 991-998. 